\title{
Experimental and numerical investigation of impinging multi-jet system
}

\author{
A. Zerrout*, A. Khelil**, L. Loukarfi*** \\ *Control, Test, Measurement and Mechanical Simulation Laboratory, University of Chlef, Algeria B.P. 151, 02000 Chlef \\ (Algeria), E-mail: zerroutamar@yahoo.fr \\ **Control, Test, Measurement and Mechanical Simulation Laboratory, University of Chlef, Algeria B.P. 151, 02000 \\ Chlef (Algeria), E-mail: khelila@yahoo.fr \\ ***Control, Test, Measurement and Mechanical Simulation Laboratory, University of Chlef, Algeria B.P. 151, 02000 Chlef
}

(Algeria),E-mail: l.loukarfi@yahoo.fr

cross $^{\text {ref }}$ http://dx.doi.org/10.5755/j01.mech.23.2.13900

\section{Introduction}

Impinging jets are widely used in industrial applications, as they have the highest heat and mass transfer rates in the impingement region. Impinging jets have been widely applied in many areas such as for cooling in electrical and electronic equipments as well as for heating, drying, and freezing in food, paper and textile industries, heating steel plates, cooling turbine blades and electronic components, tempering glass, and drying papers and food products. Impinging jet introduces high velocity of fluid stream to the impinged surface, leading to the high momentum transport and consequently high heat transfer rate on the surface [1, 2]. Several experimental and numerical studies have shown the ability to improve the heat transfer through the implementation of multiple swirling jet system. Swirling jets are widely encountered in engineering facilities, e. $g$. cyclone combustors, combustion engines, tangentially fired furnaces, and swirl burners. They are often utilized to improve heat transfer in heating, ventilation, and cooling systems. When high heat transfer coefficients are needed over a wide area, swirling jets are usually used for heat transfer devices. These, they presents an interesting flow pattern for practical and theoretical outlooks. Such configurations can be used extensively in many structures and industrial applications, $e$. g. air conditioning, drying of food products, textiles, films, papers, and burners and many others [3,4,5]. The effects of the orifice arrangement for both single and multiple jets as well as the geometries of the impinged surface on heat transfer have been studied by both numerical and experimental investigation. The local structure of turbulent swirling impinging jets is investigated experimentally by Nuntadusit et al. [1]. They concluded that over the range investigated, the maximum Nusselt number is found with multiple swirling impinging jets at the jet-to-jet distance $S / D=4$. Stephane Maurel et al [6] were concluded that the development of a general correlation can predict the evolution of the axial velocity whatever the thickness of the jet and the distance to the impact. According to the distance $\mathrm{H}$ from the impact wall and the initial thickness of the jet, the development will be relatively differently because of confinement that determines the expansion of the jet. The results are compared and validated with experimental measurements obtained by laser Doppler anemometry. A stereo PIV (Particle image velocimetry) technique using advanced preand post-processing algorithms is implemented for the experimental study of the local structure of turbulent swirling impinging jets were used by Sergey and al [7]. They examined the influence of the PIV(Particle image velocimetry) finite spatial resolution on the measured dissipation rate and velocity moments and analyzed and compared with theoretical predictions. For this purpose, they realized a special series of 2D PIV(Particle image velocimetry) measurements was carried out with vector spacing up to several Kolmogorov length scales. It was found that the magnitude of pressure diffusion decreased with the growth of the swirl rate. In general, the studied swirling impinging jets had a greater spread rate and a more rapid decay in absolute velocity when compared to the non-swirling jet. According to Huang and El-Genk [8], the circular conventional impinging jets enhance heat transfer, but produce non uniform azimuthal distributions of the local and surface average Nusselt numbers. In these bell-shaped azimuthal distributions, Nusselt numbers peak at or near the stagnation point, then drop exponentially with azimuthal distance from the stagnation point. Roux et al [9] devoted to the experimental investigation of dynamics during turbulent round jet impingement for a Reynolds number of 28000 and a distance of 5 diameters of impact, the jet is excited by a high speaker on a range of Strouhal number ranging from 0 to 1.5 , thereby changing the dynamic structure of the jet. Various analysis tools have been applied in order to observe the influence of acoustic forcing on the coherent structures of the flow. According to Goldstein et al [10] and Gauntner et al. [11] the flow field down into four parts:

- Region I: The region of established flow from the injection to the end of the cone orifice potential;

- Region II: the established flow zone characterized by the weakening of the axis velocity and development of the jet;

- Region III: the deflection region where the jet is deflected from its initial axial direction;

- Region IV: the wall jet region where the velocity is primarily azimuthal and where the boundary layer whose thickness increases azimuthally, is subject to virtually zero pressure gradients (Fig. 1).

The detailed experimental and numerical investigation of the mean flow field behavior of an isothermal turbulent impinging jet in a room has been carried out by Chen et al. [12]. They found that the comparisons between the predictive results and the experimental data reveal that both of the tested turbulence models are capable of capturing the main qualitative flow features satisfactorily. They mentioned that the predictions from the Re-Normalisation 


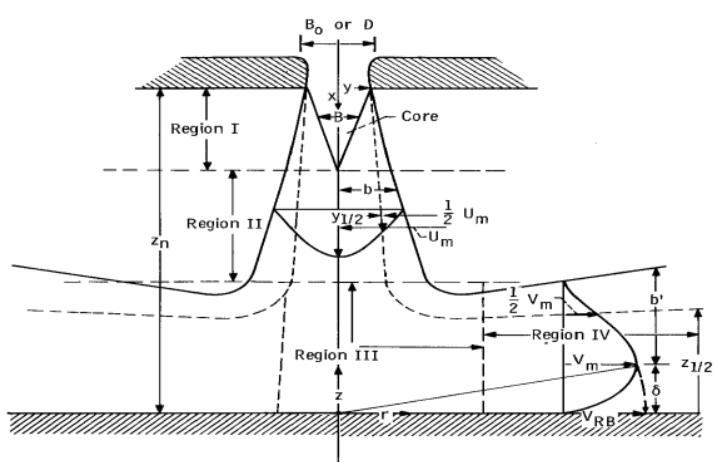

Fig. 1 Diagram of Characteristic regions in impinging jet flow $[10,11]$

Group (RNG) $k-\varepsilon$ model predicts slightly better of the maximum velocity decay as jet approaching the floor, while the The shear stress transport (SST) $k-\omega$ model accords slightly better in the region close to the impingement zone which is crucial for spreading of the jet inside the room. The work presented in this study is an experimental study of the impact of a multi-jet system on a flat plate. The realization of this original experimental bench in order to show that the examined parameters (imbalance in temperature) have a significant effect on the flow characteristics.

\section{Experimental setup}

The realized experimental device consists of a frame of the cubic form 5 of metal with dimensions $(1.20 \mathrm{~m}$ x $1.20 \mathrm{~m} \mathrm{x} 2.0 \mathrm{~m}$ ) [4]; having at its upper part the devices for blowing hot air (hair dryer), directed from the top down to the bottom and different types of diffusers 1 depending on the configuration studied part. This device allows scanning the maximum space provided by a particular arrangement of the rods supporting the thermal sensors 2 ; the tem-

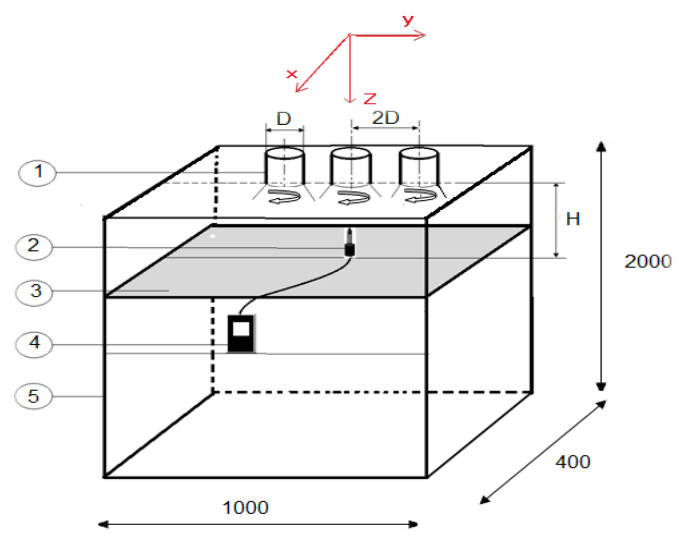

a

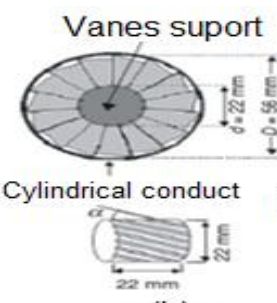

(b)

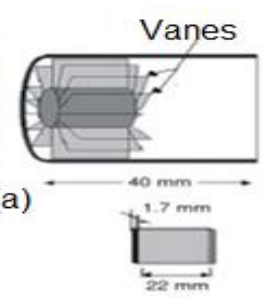

(c) (a) Swirling generator, (b) Vane support, (c) Vane

a

Fig. 2 a - Experimental facility and test assembly; b - schematic of swirling generator device perature field is explored with a portable anemometer unit Velocicalc plus 4 . The probe rods are supported by easily guided vertically and horizontally to scan the maximum space, a horizontal plate 3 material formica. The ambient temperature $T_{a}$ is obtained from the measurements of temperature $T$ in different parts of the jet. The temperature at the origin blowing $T_{\max }$ is raised for each type and configuration of the jet (Fig. 2).

\subsection{The swirl number}

The swirl is characterized by a dimensionless number that defines a measure of the ratio between the angular momentum $G_{\theta}$ and the axial momentum $G_{x}$ [13]:

$$
S=\frac{G_{\theta}}{R G_{x}}=\frac{\int_{0}^{R} r^{2} U W d r}{R \int_{0}^{R} r\left(U^{2}-\frac{W^{2}}{2}\right) d r},
$$

where $S$ is swirl number; $G_{\theta}$ is angular momentum flux, $\mathrm{kg} \mathrm{m} \mathrm{s}^{-1} ; G_{x}$ is axial momentum flux, $\mathrm{kg} \mathrm{m}^{2} \mathrm{~s}^{-1} ; R$ is diffuser radius, $\mathrm{m} ; r$ and $x$ are axial and radial distance, $\mathrm{m}$.

The swirl number can be evaluated at any position of the jet because the two quantities are calculated. Swirling helps promote and improve the process of mixing and transfer, as well as the jet has the advantage of quickly flourish in free jets. This number $S$ can be written as according to [15] as follows:

$$
S=\frac{2}{3}\left[\frac{1-\left(R_{h} / R_{n}\right)^{3}}{1-\left(R_{h} / R_{n}\right)^{2}}\right] \cdot \operatorname{tg} \alpha
$$

where $\alpha$ is the angle of the fins built swirl generator; $R_{h}$ is the radius of the vane diffuser support; $R_{n}$ is the radius of diffuser.

Note that in the case of a swirler without hub $R_{h}=0$, the expression becomes according to [14]:

$$
S=\frac{2}{3} \operatorname{tg} \alpha
$$

In this study, the axial and tangential velocities $W$ and $U$, respectively, were measured at the outlet of a diffuser with a swirling jet hot wire anemometer triple probes.

\subsection{Operating conditions}

The experimental setup was placed in a local having the following dimensions: Length $=4 \mathrm{~m}$, width $=3.5 \mathrm{~m}$ and height $=3 \mathrm{~m}$. There must be a free flow of the isolation and testing, the initial temperature at the blowing diffuser was $90^{\circ} \mathrm{c}$ for each jet.

\subsection{Measurement procedure}

The values of the initial temperature $T_{i}$ and the flow value of the ambient temperature $T_{a}$ measured by the temperature sensors of precision (1/100). They are raised until 
the temperature stabilizes. The ten minute delay was sufficient to achieve this stabilization, after measuring, the temperatures for a given configuration, and the pairs of blowing is stopped and the movement of the rods proceeds door sensors to other measurement point.

\subsection{Measurement errors}

The reduced temperature $T_{r}$ of measurement is obtained by reference to the maximum average temperature at the outlet of the blowing diffusers and at room temperature:

$$
T_{r}=\left(T_{i}-T_{a}\right) /\left(T_{\max }-T_{a}\right),
$$

where $T_{r}$ is dimensionless temperature, $\mathrm{K} ; T_{a}$ is ambient temperature, $T_{\max }$ is maximum temperature at the diffuser exit $k$.

Reduced dimensionless axial velocity is obtained with respect to the maximum velocity at the outlet of the blowing port.

$$
U_{r}=U_{i} / U_{\max },
$$

where $U$ is axial mean velocity, $\mathrm{m} / \mathrm{s} ; U_{\max }$ is maximum velocity at the diffuser exit, $\mathrm{m} / \mathrm{s} ; U_{r}$ is dimensionless axial velocity, $\mathrm{m} / \mathrm{s}$.

Similarly, the azimuthally and axial distances are given by reference to the diameter of the blowing diffuser in dimensionless form $r / R$ and $x / D$. The accuracy for the calibration of the temperature is at least 6: 1 in accordance with the characteristics of the precision of the calibrated devices. The accuracy for the calibration of the pressure is at least the ratio 2.5: 1 in accordance with the characteristics of the precision of the calibrated devices. The accuracy for the calibration of the velocity is at least 1: 1 in accordance with the characteristics of the precision of the calibrated devices. The results of the calibration tests of the anemometer portable device VELOCICALC plus are percentages of tolerance which the temperature is $\pm 0.3^{\circ} \mathrm{C}$ of reading, the pressure is $\pm 1.0 \%$ of reading, velocity is $\pm 3 \%$ of reading. The heat transfer from the impinging jets is characterized by the Nusselt number. It is a dimensionless number that quantifies the heat transfer between a fluid and a wall of the baffle plate. It represents the ratio of convective exchanges on conductive exchanges [15]:

$$
N_{u}=h L / \lambda,
$$

where $H$ is local convective heat transfer coefficient, $\mathrm{W} \mathrm{m}^{-2} \mathrm{~K}^{-1} ; \lambda$ is the thermal conductivity of air, taken at the reference temperature, $\mathrm{W} \mathrm{m}^{-1} \mathrm{k}^{-1} ; L$ is length of the plate, $\mathrm{m}$. It is calculated by an empirical formula:

$$
N_{u}=0.332 \operatorname{Re}^{\frac{1}{2}} \operatorname{Pr}^{\frac{1}{3}},
$$

where $R_{e}$ is the Reynolds number.

It is defined by:

$$
R_{e}=\rho U D / \mu
$$

where $\rho$ is density of air; $U$ is average velocity, $\mathrm{ms}^{-1} ; D$ is hydraulic diameter, $\mathrm{m}$; $P_{r}$ is Prandtl number is a dimensionless number, it represents the ratio of momentum diffusivity and thermal diffusivity:

$$
p_{r}=\mu C_{P} / \lambda,
$$

where $\mu$ is dynamic viscosity, $\mathrm{Nsm}^{-2} ; C_{p}$ is specific heat, $\mathrm{Jkg}^{-1} \mathrm{~K}^{-1} ; \lambda$ is air thermal conductivity, $\mathrm{Wm}^{-1} \mathrm{k}^{-1}$.

\subsection{Different types of diffuser configuration}

It is interesting to note that we mainly considered the evolution of the temperature profiles for axial and azimuthally multiple swirling jets in five separate configurations designated as $\mathrm{A}, \mathrm{B}, \mathrm{C}, \mathrm{D}$ and $\mathrm{E}$. The configurations comprised three swirling jets in balanced $\mathrm{B}$ and $\mathrm{E}$ and imbalanced $\mathrm{C}$ and $\mathrm{D}$ in temperature and velocity, as well as a single swirling jet configuration $\mathrm{A}$, which are shown in Fig. 3 and in Table 1.

Table 1

Different types of diffuser configuration

\begin{tabular}{|c|c|c|c|c|}
\hline $\begin{array}{c}\text { Config- } \\
\text { ura- } \\
\text { tions }\end{array}$ & $\begin{array}{r}\text { Number } \\
\text { of out- } \\
\text { let jets }\end{array}$ & $\begin{array}{r}\text { Temperature } \\
\text { distribution }\end{array}$ & $\begin{array}{c}\text { Velocity dis- } \\
\text { tribution }\end{array}$ & $\begin{array}{c}\text { Swirling direction } \\
\text { of the central jet }\end{array}$ \\
\hline A & 1 & $\mathrm{~T}$ & $\mathrm{U}$ & ---- \\
\hline B & 3 & $(\mathrm{TTT})$ & $(\mathrm{U}, \mathrm{U}, \mathrm{U})$ & Same direction \\
\hline $\mathrm{C}$ & 3 & $(\mathrm{~T}, \mathrm{~T} / 2, \mathrm{~T})$ & $(\mathrm{U}, \mathrm{U} / 2, \mathrm{U})$ & Same direction \\
\hline $\mathrm{D}$ & 3 & $(\mathrm{~T} / 2, \mathrm{~T}, \mathrm{~T} / 2)$ & $(\mathrm{U} / 2, \mathrm{U}, \mathrm{U} / 2)$ & Same direction \\
\hline $\mathrm{E}$ & 3 & $(\mathrm{~T}, \mathrm{~T}, \mathrm{~T})$ & $(\mathrm{U}, \mathrm{U}, \mathrm{U})$ & Opposite direction \\
\hline
\end{tabular}

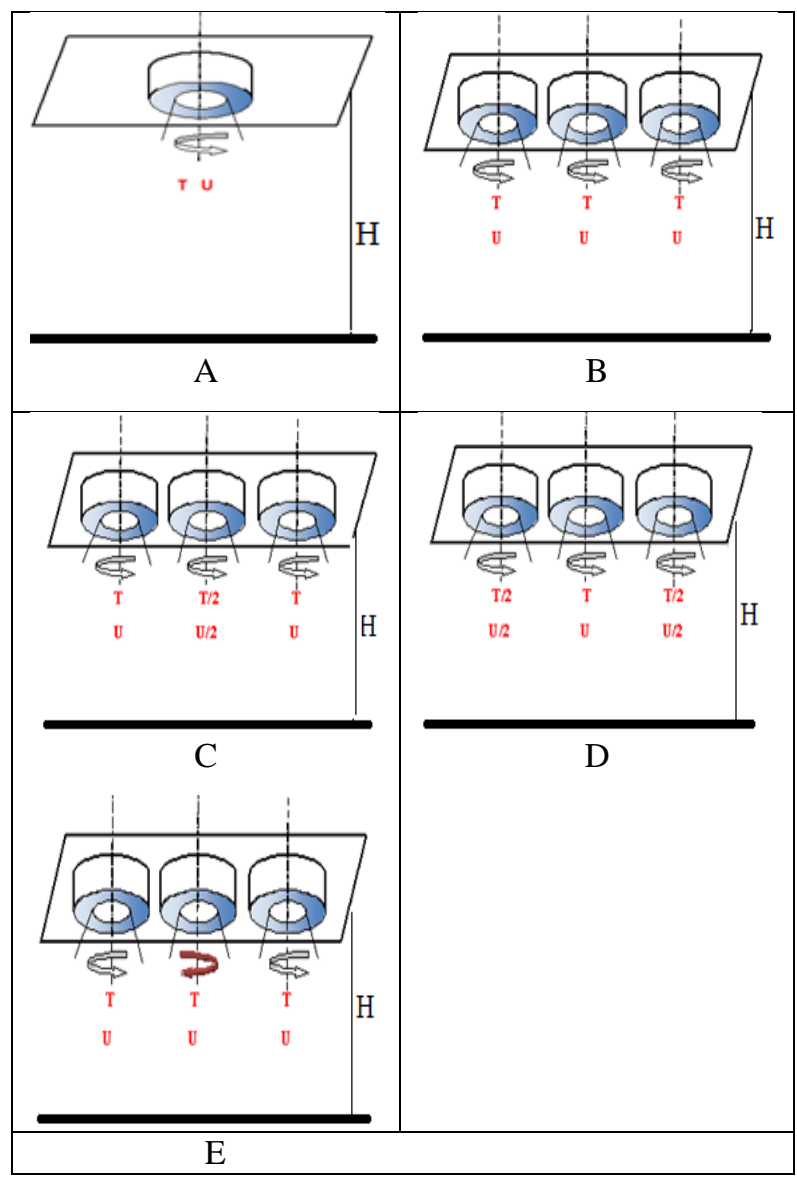

Fig. 3 Different types of diffuser configuration 


\section{Numerical procedure}

For a steady, three-dimensional, incompressible, and turbulent flow with constant fluid properties, the governing equations of conservation of mass, momentum and energy are written in the Cartesian tensor notation as follows:

$$
\begin{gathered}
\frac{\partial U_{i}}{\partial x_{i}}=0 \\
\rho \frac{\partial\left(U_{i} U_{j}\right)}{\partial x_{j}}=-\frac{\partial P}{\partial x_{i}}+\frac{\partial}{\partial x_{j}}\left[\mu\left(\frac{\partial U_{i}}{\partial x_{j}}+\frac{\partial U_{j}}{\partial x_{i}}\right)-\overline{\rho u_{i}^{\prime} u_{j}^{\prime}}\right], \\
\rho C_{p} U_{i} \frac{\partial T}{\partial x_{i}}=\frac{\partial}{\partial x_{i}}\left[\lambda \frac{\partial T}{\partial x_{i}}-\rho C_{p} \overline{u_{i}^{\prime} T^{\prime}}\right]
\end{gathered}
$$

where $U_{i}$ and $T$ are denote the mean velocity and temperature; $u_{i}^{\prime}, u_{j}^{\prime}$ and $T^{\prime}$ are the corresponding fluctuation components; $-\rho \overline{u_{i}^{\prime} u_{j}^{\prime}}$ and $-\rho C_{p} \overline{u_{i}^{\prime} T^{\prime}}$ are the average Reynolds stresses and turbulent heat fluxes which need to be modelled to close the equations [16], [17] and [18].

It should be noted that here, the temperature variations are negligible and the Mach number is low $(<0.3)$, which allows us to assume that the fluid is incompressible (constant density).

The Boussinesq hypothesis, which relates the Reynolds stresses to the mean velocity gradients, is expressed as:

$$
-\rho \overline{u_{i}^{\prime} u_{j}^{\prime}}=\mu_{t}\left(\frac{\partial U_{i}}{\partial x_{j}}+\frac{\partial U_{j}}{\partial x_{i}}\right)-\frac{2}{3}\left(\rho k+\mu_{t} \frac{\partial U_{i}}{\partial x_{i}}\right) \delta_{i j},
$$

where $k$ is the turbulent kinetic energy, as defined by $k=\frac{1}{2} \overline{u_{i}^{\prime} u_{i}^{\prime}}$, and $\delta_{i j}$ is the tensor identity. An advantage of the

Boussinesq approach is the relatively low computational cost associated with the computation of the turbulent viscosity $\mu_{t}$. Note that the turbulent viscosity $\mu_{t}$ is given by:

$$
\mu_{t}=C_{\mu} \rho K^{2} / \epsilon,
$$

with $k$ and $\epsilon$ are kinetic and dissipation energy respectively. Hence in the present calculation, the turbulence scalar fluxes are modelled using the gradient-diffusion approach [19], [20] as:

$$
\rho C_{p} \overline{u_{i}^{\prime} T^{\prime}}=-\frac{C_{p} \mu_{t}}{\sigma_{t}} \frac{\partial T}{\partial x_{i}},
$$

where $\sigma_{t}=0.6$ stands for the turbulent Prandtl number.

The $k-\varepsilon$ model is an example of two equation models that use the Boussinesq hypothesis. Here, two different closure models, $k$ - $\varepsilon$ model.

The boundary conditions are needed for the numerical simulation and can have a significant effect on the numerical results. Table 2 depict the different boundary conditions introduced in the calculation code (Table 2).

Boundary conditions

\begin{tabular}{|c|c|}
\hline Variable & Boundary conditions \\
\hline Turbulence intensity & $4 \%$ \\
\hline Relaxation factor & Pression $=0.3$, Density $=0.5$, Energy $=1$, Other parameters $=0.6$ \\
\hline Convergence criteria & Energy $=10^{-6}$, Other parameters $=10^{-4}$ \\
\hline Inlet conditions & $U=10 \mathrm{~ms}^{-1}, T_{0}=363^{\circ} \mathrm{K}$, \\
\hline Hydraulic diameter & $D_{h}=0.047 \mathrm{~m}$ \\
\hline Inlet pressure & Standard \\
\hline
\end{tabular}

The numerical simulation has been performed with a tetrahedral and unstructured mesh composed of 1201672 cells. A more detailed discretization was used close to the inlets of burner and to the axis to give high resolution where required and to save the computational effort and time calculation. Tests with finer grids (up to 1547214 cells) demonstrate that the quality of the prediction is not improved by enhancing the number of cells used is shown in Table 3. Computations on different mesh have shown that the solution of the axial velocity does not change significantly $(\leq 4 \%)$.

Table 3

\begin{tabular}{|c|c|c|c|c|}
\hline Cell number & 520355 & 865421 & 1201672 & 1547214 \\
\hline Nodes number & 105476 & 166655 & 226284 & 287445 \\
\hline
\end{tabular}

\section{Results and discussion}

This section is devoted to an extensive study of dimensionless temperature profiles depending on dimensionless azimuthal direction $y / D$ variation for the different measuring stations. The influence of other parameters are

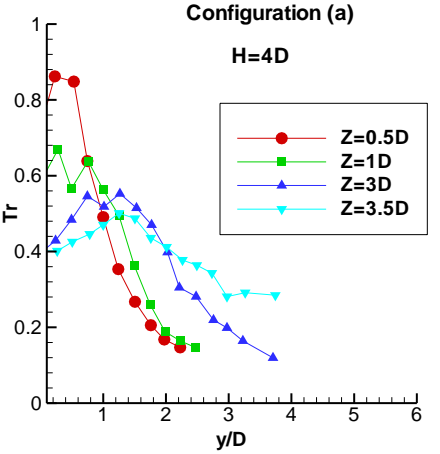

Fig. 4 Profiles of azimuthal dimensionless temperature for configuration A

examined as the variation of the height of the impact plate $(2 D, 4 D, 6 D$ and $8 D)$ for studied configurations (single jet and three jets) and the variation of the temperatures and velocities just outside the diffuser. The profiles of azimuthal dimensionless temperature for configuration $\mathrm{A}$ 


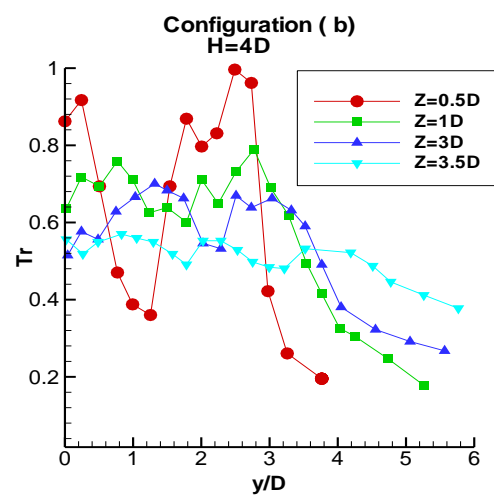

Fig. 5 Profiles of azimuthal dimensionless temperature for configuration B

are showed in Fig. 4. The Fig. 4 shows that the temperature decreases rapidly in the azimuthal direction from a maximum value close to the blowing orifice to a minimum value near the impact surface. We also note that the diffuser single jet (configuration $\mathrm{A}$ ) gives a low recirculation zone and a smaller azimuthally spreading compared to multi jets as shown in Figs. 5 and 6. The azimuthal development of the single jet (configuration A) reaches a ratio of 4 to 5 times the diameter in comparison with the multi jets of three diffusers as the development up to 6 times of diameter. The Fig. 5 shows the dimensionless temperature profiles that exhibit in the first stations the amplitude peaks at the diffuser exit. A decrease is due to the distance of the diffuser orifice and jets mixing. In the other stations, the amplitudes of the impoverished temperature from one station to another to reach the impact temperature of the deflection jet zone. The temperature profiles become almost parallel to the obstacle, the azimuthal temperature amplitudes impact is then

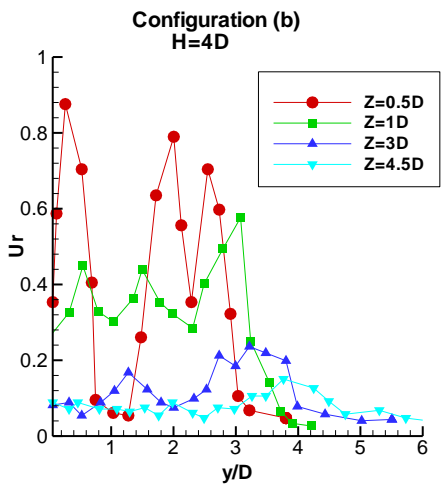

Fig. 6 Profiles of axial dimensionless velocity for configuration $\mathrm{B}$

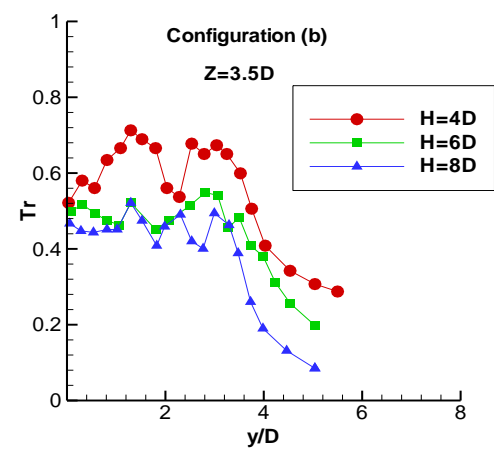

Fig. 7 Influence of the impact height on the plate temperature for configuration B reduced. The ambient temperature increased slightly. The spreading of the global jet is important than the diffuser with swirling single jet. The average axial velocity profiles of the configuration B are shown in Fig. 6.

We note the existence of peaks of amplitudes at each diffuser orifice, these amplitudes decrease from one station to another until that the velocity profiles becomes almost parallel to the impinging plate. In the presence of the plate impacts, fluid particles change direction. The area of impact increases the azimuthal growth of the global jet. The presented results show the decrease of the mean axial velocity of the jet at the impact plate. This is partly due to the turbulence and the obstacle that produces a large azimuthal development of the jet while approaching the wall region.

Fig. 7 shows the dimensionless temperature profiles in the near impact stations for impact heights: $4 D, 6 D$, and $8 D$. It is noted that when the height $H$ increases, more uniform temperature distribution is obtained over the entire surface of the plate. If $H$ is the minimum, a maximum temperature is obtained on the central zone, which is unwanted for the heating or cooling for premises. Fig. 8 presents the dimensionless temperature profiles in the stations closest to the impact plate. The influence of the parameter of temperature imbalance on the azimuthal distribution of temperature near the impact plate was studied.

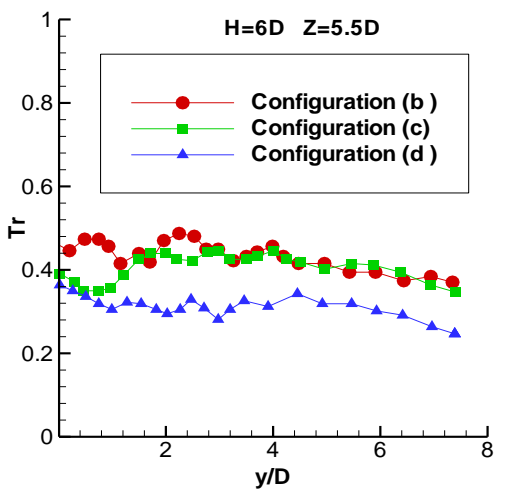

Fig. 8 Dimensionless temperature for configuration B, C and $\mathrm{D}$

We examined the different inlet temperature conditions of configuration $\mathrm{D}(\mathrm{T} / 2, \mathrm{~T}, \mathrm{~T} / 2)$, Configuration $\mathrm{C}(\mathrm{T}$, $\mathrm{T} / 2, \mathrm{~T})$ and configuration $\mathrm{B}(\mathrm{T}, \mathrm{T}, \mathrm{T})$. It is noted that the diffuser of the configuration $\mathrm{B}(\mathrm{T}, \mathrm{T}, \mathrm{T})$ gives a good temperature distribution on the surface of the plate. The Azimuthal dimensionless temperature and velocity profiles of configuration $\mathrm{B}$ and configuration $\mathrm{E}$ respectively are shown in Fig. 9. The influence of the rotation sense of the central swirling diffuser was been examined. We note that the temperature increases the lateral ends of the jets through the reverse swirl that influences the azimuthal development of the jet from one station to another. Comparing with the diffuser same sense of swirling temperature profiles in stations near the surface impacts the reverse swirl central jet, causes a slight increase in temperature to the heights impact $2 D$ and $4 D$.

Attempt to clarify the distribution of Nusselt number noted $(\mathrm{Nu})$ on the plate is presented in Fig. 10. The Nusselt Number is a dimensionless number which quantifies the heat transfer between a fluid and a wall of the impact 
plate. It represents the ratio of convective exchanges on conductive exchanges. The azimuthal profile of the Nusselt number (Fig. 10), has a peak at about 1D to the jet axis, and decreases with distance from the jet. A second peak at about $3 \mathrm{D}$ axis of the jet appears, it says that the convective transfer increases in areas of separation of jets, Nusselt curves become almost parallel to the plate when approaching the impact plane.

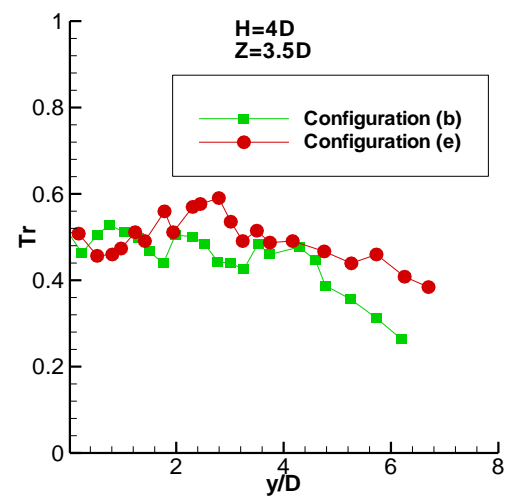

a

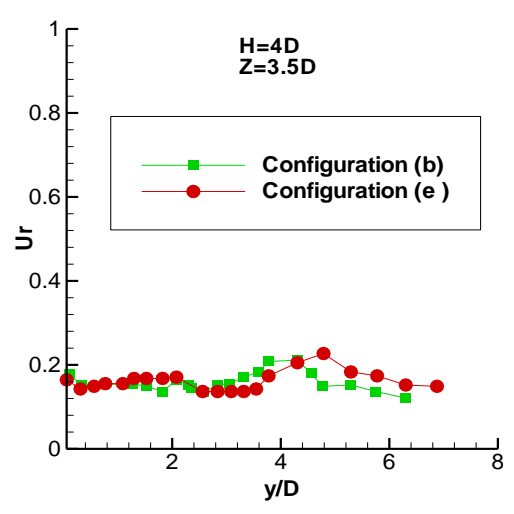

b

Fig. 9 Influence of the direction of rotation of the central jet on: a - the dimensionless temperature $T_{r}, \mathrm{~b}$ - the dimensionless velocity $U_{r}$

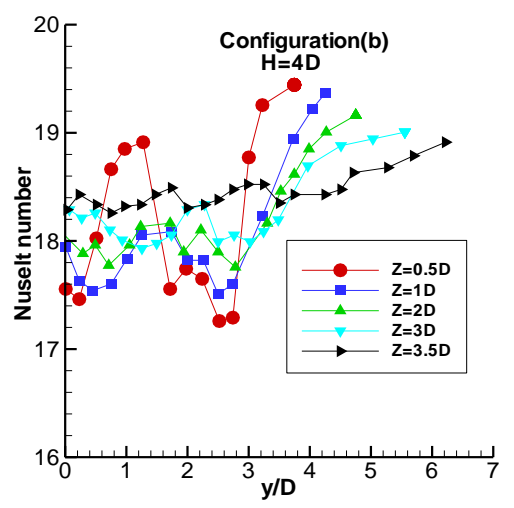

Fig. 10 Profiles of the azumithal Nuselt number at different axial locations for configuration $\mathrm{B}$

The multiple swirling impinging a flat plate jet system was simulated numerically by means of the turbulence model $k-\varepsilon$. It gave results of comparison of temperature and velocity profiles with those granted to the experimental results (Fig. 11). This study allowed us to find thermal characteristics of the multiple swirling impinging jets. The quali-

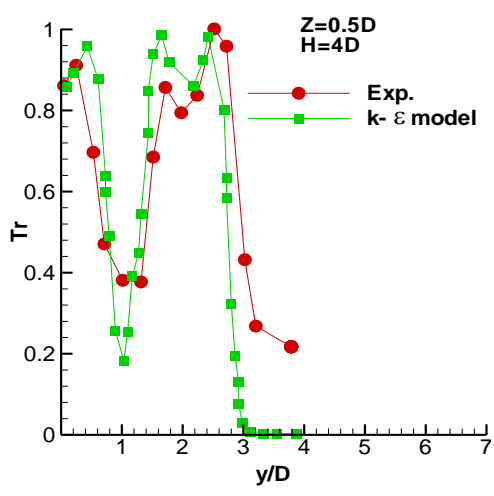

a

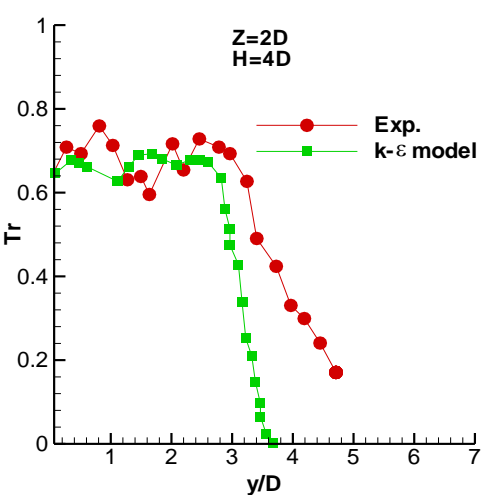

$\mathrm{b}$

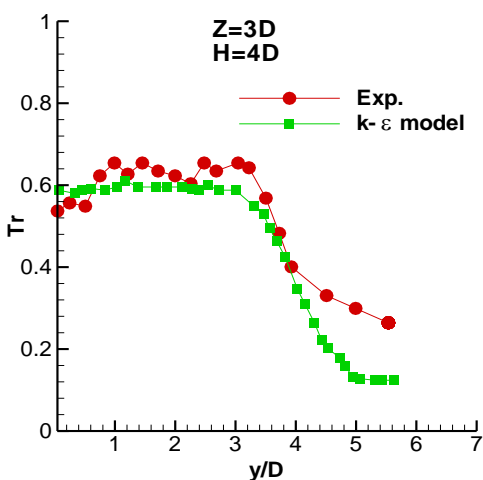

$\mathrm{e}$

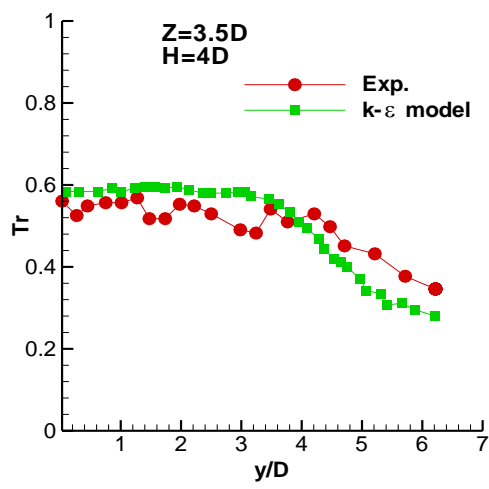

d

Fig. 11 Comparison of numerical and experimental azimuthal distribution of dimensionless temperature for configuration $\mathrm{D}$ at stations $Z=0.5$ (a), 2 (b), 3 (c) and 3.5 (d) 


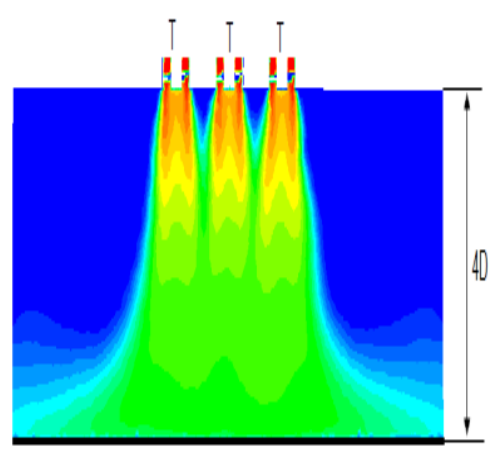

a

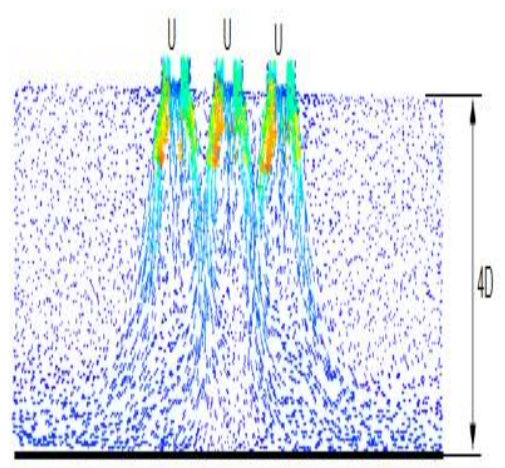

b

Fig. 12 a - contour temperature field; b - velocity field vectors at height of impact $4 D$ for configuration $\mathrm{B}$

ty of comparison between the numerical results and the experimental results is demonstrated in Fig. 12, this comparison shows that the model with two transport equations $k-\varepsilon$ used to simulate this case produces results satisfactory. Despite the weaknesses of the model $k-\varepsilon$, the latter gave acceptable results qualitatively. Nevertheless, it is a relatively simple simulation tool inexpensive to use.

Fig. 12, describes the temperature and velocity vector field for configuration $\mathrm{B}$ with a impact height of $4 D$. we note that the multi jet system is present as a free jet in the blowing region, is the established flow region from the injection orifice to the end of the cone potential then it is characterized by weakening of the velocity on the axis and development hence the established flow zone, then the jet is deflected from its initial direction is axial deflection region. Finally, velocity is mainly azimuthal and where the boundary layer, whose thickness increases azimuthal so called the wall jet region.

\section{Conclusion}

The experimental and numerical investigation of the impact of the swirling multi-jet system on a flat plate has been realized. To carry out this study, it was necessary at first to design and achieve an original experimental a test bench with three diffusers arranged in line. The diameter between the axes of their centers is fixed at $2 D$. The experiments were conducted with four different jet distances to impinging plate $(H=2 D, 4 D, 6 D$ and $8 D)$. The swirling jet is obtained by a generator consists of 12 arranged vanes at $60^{\circ}$ from the vertical placed just the diffuser exit. We can say that a key objective in a configuration of multi-jet swirling system is to access the perfect mix as quickly as possible with a very high heat transfer from the plate. The optimum configuration of a system of multiple jets depends on the type of the following parameters: the impact of height, the diffuser inlet temperatures, air flow at the inlet diffusers and the direction of the central swirling jet.

The diffuser having a temperature distribution $(\mathrm{T}$, $\mathrm{T}, \mathrm{T}$ ) with a reverse direction of the swirl and a central jet impact height $H$ between $4 D$ and $6 D$ ensures uniform distribution of temperature along the plate and promotes better the development of the jet. From the standpoint of thermal homogenization, the optimization of parameters such as geometry configuration (air diffuser, high impact, jet and plurality of swirl direction of the central jet) clearly shows a temperature distribution over the entire surface plate while allowing the diffusion and development of the largest multijet system. The ultimate goal of the numerical methods is to reduce the number of experimental tests. The comparison between the numerical results and experimental results presented in this study indicates that the two-equation model of transport $(k-\varepsilon)$ produced satisfactory results. Despite the weaknesses of the model $(k-\varepsilon)$, the latter gave acceptable results qualitatively. It remains an inexpensive tool to use relatively simple simulation.

\section{References}

1. Nuntadusit, C; Wae-hayee, M; Bunyajitradulya, A; Eiam sa-ard, S. 2012. Heat transfer enhancement by multiple swirling impinging jets with twisted-tape swirl generators. International Communications in Heat and Mass Transfer 39: 102-107.

http://dx.doi.org/10.1016/j.icheatmasstrans-

fer.2011.10.003.

2. Salman, S.; Kadhum, A; Takriff, M.; Mohamad, A. 2014. Experimental and numerical investigations of heat transfer characteristics for impinging swirl flow. Hindawi Publishing Corporation Advances in Mechanical Engineering, Article ID 631081.

3. Braikia, M; Loukarfi, L; Khelil, A; Naji, H. 2012. Improvement of thermal homogenization using multiple swirling jets. Thermal Science 16(1): 237-248. http://dx.doi.org/ 10.2298/tsci101026131b.

4. Roudane,M; Loukarfi, L; Khelil, A; Hemis, M. 2013. Numerical investigation of thermal characteristics of confined rotating multi-jet. Mechanics \& Industry 14(04): 317-324. http://dx.doi.org/10.1051/meca/2013071.

5. Khelil, A; Naji, H; Braikia, M; Loukarfi, L. 2015. Comparative investigation on heated swirling jets using experimental and numerical computations. Heat Transfer Engineering 36(1): 43-51.

http://dx.doi.org/10.1080/01457632.2014.906279.

6. Maurel, S; Rey, C; Solliec, C. 2001. Comparison modeling experience in the case of a turbulent air jet impinging a plate planes, School of Mines Nantes. XV ${ }^{\text {th }}$ French Congress of Mechanics Nancy, 3 to 7 (September 2001).

7. Alekseenko, S.V; Bilsky,A.V; Dulin,V.M; Dmitriy M; Markovich, D.M. 2007. Experimental study of an impinging jet with different swirl rates. International Journal of Heat and Fluid Flow. 28:1340-1359. http://dx.doi.org/10.1 016/j.ijheatfluidflow.2007.05.011 
8. HUANG, L; EL-GENK, M. S. 1998. Heat transfer and flow visualization experiments of swirling, multi-channel, and conventional impinging jets. International Journal of Heal Mass Transfer 41(3): 583-600. http://dx.doi.org/10.1016/S0017-9310(97)00123-3.

9. ROUX, S; BRIZZI, L.E; DORIGNAC, E. 2009. Dynamics of a round jet impinging a flat wall constrained by acoustic forcing, Studies Laboratory Thermal, ENSMA. University of Poitiers, 40109 CNRSBP. 19th French Congress of Mechanics Marseille.

10. Goldstein, R.J; Franchett, M.E. 1988. Heat transfer from a flat surface to an oblique impinging jet. ASME. Journal of Heat Transfer 110: 84-90. http://dx.doi.org/10.1115/1.3250477.

11. Gauntner, J.W; Livingood, J.N.B; Hrycak, P. 1970. Survey of literature on flow characteristics of a single turbulent jet impinging on a flat plate. technical Report, NASA.

12. Chen, H.J; Moshfegh, B; Cehlin, M. 2012. Numerical investigation of the flow behavior of an isothermal impinging jet in a room. Building and Environment 49: 154-166. http://dx.doi.org/10.1016/j.buildenv.2011.09.027.

13. Gupta, A.K; Lilley, D.G; Syred, N. 1984. Swirl flows. London. Ab acus Press.

14. Huang, Y; Yang, V. 2009. Dynamics and stability of lean-premixed swirl-stabilized combustion, Progress in Energy and Combustion Science 35: 293-364. http://dx.doi.org/10.1016/j.pecs.2009.01.002.

15. Wigley, G; Clark, J.A. 1974. Heat transport coefficients for constant energy flux models of broad leaves. Boundary- Layer Meteorology 7: 139-150. http://dx.doi.org/10.1007/BF00227909.

16. Seok-Ki, C. and Seong, O.K. 2012. Turbulence modeling of natural convection in enclosures: A review. Journal of Mechanical Science and Technology 26 (1): 283297. http://dx.doi.org/10.1007/s12206-011-1037-0.

17. Koseoglu, M.F.; Baskaya, S. 2008. The effect of flow field and turbulence on heat transfer characteristics of confined circular and elliptic impinging jets. International Journal of Thermal Sciences 47: 1332-1346. http://dx.doi.org/10.1016/j.ijthermalsci.2007.10.015.

18. Kazuya, T.; Miyako, T.; Peter, L.W.; Kazuyoshi. N. 2010. Swirl and buoyancy effects on mixing performance of baffle-plate-type miniature confined multijet. International Journal of Heat and Fluid Flow 31: 45-56. http://dx.doi.org/10.1016/j.ijheatfluidflow.2009.09.005

19. Wasewar, K.L; Sarathi, J.V. 2008. CFD modelling and simulation of jet mixed tanks. Engineering Applications of Computational Fluid Mechanics 4(3): 374-386. http://dx.doi.org/10.1080/19942060.2008.11015218.

20. El Drainy, Y.A; Saqr, K.M.; Aly, H.S; Mohd Jaafar, M.N. 2009. CFD Analysis of incompressible turbulent swirling flow through zanker plate. Engineering Applications of Computational Fluid Mechanics 3(4): 562572.

http://dx.doi.org/10.1080/19942060.2009.11015291.
A. Zerrout, A. Khelil, L. Loukarfi

\section{EXPERIMENTAL AND NUMERICAL STUDY OF SWIRLING MULTI-JET SYSTEM IMPINGING A FLAT PLATE}

S u m m a r y

The main emphasis of the present work is the experimental and numerical analysis of the impact of the swirling multi-jet system on a flat plate. To carry out this study, it was necessary at first to design and achieve an original experimental a test bench with three diffusers arranged in line. The diameter between the axes of their centers is fixed at $2 D$. The experiments were conducted with four different jet distances to impinging plate $(H=2 D, 4 D, 6 D$ and $8 D)$. The swirling jet is obtained by a generator consists of 12 arranged vanes at $60^{\circ}$ from the vertical placed just the diffuser exit. The current study is carried out under uniform heat flux condition for each diffuser at Reynolds number of $30 \cdot 10^{3}$, the air being the working fluid. Experiences concerning the fusion of several jets show that the resulting jet is clearly more homogenized under swirling influence. In this perspective, the paper discusses influence of different factors such as the multi swirling jets, the impact height, the conditions for entries temperatures and velocities, and the swirl direction of the central jet on the effectiveness of ventilation performance and optimizing the best configuration. The CFD investigations are carried out by an unstructured mesh to discretize the computational domain. In this work, the simulations have been performed using the finite volume method, in which the standard $k-\varepsilon$, is used for turbulence computations. The validation shows that the $K-\varepsilon$ model can be used to simulate this case successfully. The results show that the examined parameters have a significant effect on the flow characteristics and behavior of multi swirling impinging jet.

Keywords: swirling jet; impinging jet; multiple jet; thermal homogenization.

Received December 30, 2015 Accepted April 14, 2017 